\title{
SWALLOWING DISORDERS DURING AND AFTER THE TREATMENT OF LARYNX CANCER
}

\author{
Mirna Zelic ${ }^{1}$, Mirjana Petrovic Lazic ${ }^{2}$, Dragan Pavlovic ${ }^{2}$ \\ IInstitute for Psychophysiological Disorders and Speech Pathology "Prof. dr Cvetko Brajović", Belgrade, Serbia \\ ${ }^{2}$ Faculty for Special Education and Rehabilitation, University in Belgrade, Belgrade, Serbia
}

\section{POREMEĆAJI GUTANJA U TOKU I NAKON LEČENJA KARCINOMA LARINKSA}

\author{
Mirna Zelić1, Mirjana Petrović Lazić2, Dragan Pavlović ${ }^{2}$ \\ IZavod za psihofiziološke poremećaje i govornu patologiju „,Prof. dr Cvetko Brajović“, Beograd \\ ${ }^{2}$ Fakultet za specijalnu edukaciju i rehabilitaciju Univerziteta u Beogradu, Beograd
}

\begin{abstract}
Dysphagia is a swallowing disorder that is characterized by difficulty to swallow and to control saliva as well as by feeding difficulties. Dysphagia is a common symptom of laryngeal cancer, or a consequence of surgical treatment as well as radiotherapy and chemotherapy of this neoplasma. The patients after laryngectomy are at risk of developing malnutrition, and aspiration pneumonia. Removal of anatomical structures and reorganization of remaining tissues has a significant impact on the physiology of swallowing. For most patients, safe swallowing is the main feature of a positive treatment outcome. Swallowing therapy is important before, during and after treatment of larynx cancer. The aim of this paper is to explore a correlation between swallowing disorders and laryngeal cancer treatment, and to understand the anatomical and physiological bases of dysphagia treatment.
\end{abstract}

Key words: deglutition disorders; laryngeal neoplasms; therapeutics.

\section{INTRODUCTION}

Dysphagia is defined as a swallowing disorder including difficulty to swallow and control saliva as well as by feeding difficulties. In the most general terms, dysphagia encompasses all behavioral, sensory, and preliminary motor actions in preparation for swallowing, including the awareness of the impending feeding situation, visual recognition of food, and increased saliva production as a physiological response to food $(1,2)$.

Laryngeal cancer accounts for $40 \%$ of all head and neck cancers, and $2 \%$ of all cancers in the body (3). Statistics indicate that laryngeal cancer is four to five times more common in men. In relation to localization, it can be supraglottic, glottic and subglottic. The glottis is affected in $60 \%$ of cases, the supraglottic in $35 \%$, and the other $5 \%$ includes subglottic structures $(1,4)$. Exogenous risk factors influencing the occurrence of laryngeal cancer are smoking, alcohol consumption, ionizing radiation, mechanical and thermal damage to the laryngeal mucosa as well as chronic laryngitis (5).

The symptoms of laryngeal cancer depend on their location. Supraglottic carcinoma spreads rapidly and

\section{SAŽETAK}

Disfagiju definišemo kao poremećaj gutanja. Poremećaji gutanja obuhvataju kako teškoće u gutanju i kontrolisanju pljuvačke, tako i teškoće u hranjenju. Disfagija podrazumeva čest simptom karcinoma larinksa, ali i posledicu hirurškog lečenja kao i radioterapije $i$ hemoterapije ove neoplazme. Laringektomirani bolesnici su u riziku za malnutriciju $i$ pneumoniju. Uklanjanje ključnih anatomskih struktura $i$ reorganizacija preostalih tkiva ima značajan uticaj na fiziologiju gutanja. Izbor tretmana lečenja za očuvanje funkcije gutanja najvažnije je pitanje. Za većinu pacijenata bezbedno gutanje je glavna odlika pozitivnog ishoda lečenja. Tretman poremećaja gutanja je važna karika pre, u toku $i$ nakon lečenja. Cilj rada bio je da se utvrdi korelacija između poremećaja gutanja, lečenja karcinoma larinksa, laringektomije kao izbora lečenja, odnosno razumevanje anatomskih i fizioloških osnova tretmana disfagija.

Ključne reči: poremećaji gutanja; tumori grkljana; terapija.

metastasizes locally. The most significant symptom is hoarseness, but it is not the earliest. The earliest symptom is difficulty swallowing. In glottic carcinoma, hoarseness of variable intensity is the earliest symptom, while subglottic carcinoma does not give early symptoms, except for difficulty breathing, i.e. inspiratory stridor and later respiratory insufficiency. Carcinomas of the glottic region have the best prognosis precisely because of the appearance of early symptoms $(5,6)$.

Two primary approaches to the treatment of laryngeal cancer are surgical treatment and radiotherapy and they can be combined. Primary radiotherapy is less destructive to tissue and can be used in early glottic cancer (7). If the tumor is in the earliest stage, there are almost no side effects, but if there is a larger amount of radiotherapy $(6,000-7,000 \mathrm{~Gy})$, the side effects of radiotherapy are related to phonation and swallowing problems due to xerostomia, mucosal damage, thick saliva, loss of sense of taste and smell, edema, inflammatory processes of the gums and oral cavity. Chemotherapy is also applied before surgical treatment or radiotherapy, i.e. as a combination therapy with surgery. Despite the development of nonsurgical therapy to preserve organs, laryngectomy, total or 
partial is still the optimal therapy for advanced disease as the only option after unsuccessful radiotherapy. Laryngectomy as such significantly changes the quality of life with significant consequences for swallowing and speech. The first laryngectomy was performed 150 years ago, and while only a few ablative aspects have changed, reconstructive techniques have undergone radical evolution (8). The choice of treatment to preserve swallowing function is the most important issue. For most patients, safe swallowing is the main feature of a positive treatment outcome.

This paper aims to explore the correlation between swallowing disorders and laryngeal cancer treatment, with its anatomical and physiological bases. A brief overview of the normal physiology of swallowing is necessary to further analyze the impact of laryngeal cancer on the anatomical structures and functional basis of swallowing.

\section{PHYSIOLOGY OF SWALLOWING}

Eating and swallowing are complex motor actions and include voluntary and reflex activities of as many as 30 muscles and five cranial nerves and have two biological roles: 1) food transfer from the oral cavity to the stomach and 2) respiratory protection (9).

Different authors point to different divisions of swallowing phases. According to Logeman (1), swallowing has four phases: a) preparatory oral, b) oral, c) pharyngeal and e) esophageal. Other authors further break down the oral phase into three more levels: food transfer through the oral cavity, food processing by chewing and saliva, and food transfer to the oropharynx. A rough division into only three phases can be found in the literature, namely oral, pharyngeal and esophageal (10).

Eating, swallowing, and breathing are closely related. In healthy adults, breathing is interrupted during swallowing due to both the physical closure of the airways by lifting the soft palate and the closure of the epiglottis and the neural control of respiration in the brainstem. When sucking, the newborn swallows and breathes at the same time. Understanding the physiology and pathophysiology of eating and swallowing are key to the evaluation and treatment of swallowing disorders (11).

\section{Preparatory oral phase}

The patterns of movement in the preparatory oral phase vary depending on the viscosity of the food, its quantity as well as the degree of pleasantness (subjective sense of taste). At the moment when the liquid is placed in the mouth, the lips close, which requires nasal breathing, and the posterior soft palate and tongue prevent premature leakage of fluid into the pharynx. In the case of solid food, the tongue rotates laterally by placing food on the teeth due to chewing. At this stage, the food bolus is softened by saliva $(1,9,11)$.

\section{Oral phase}

During the oral phase, the tip of the tongue is raised, touches the alveolar ridge and the posterior part is lowered and opens the passage to the pharynx. The dorsal surface of the tongue moves upwards, expanding the area of contact with the palate and pressing the fluid against the palate. In the case of solid foods, the oral phase has the role of completely preparing food and facilitating the pharyngeal phase $(1,11)$.

\section{Pharyngeal phase}

The pharyngeal phase begins with the trigger of the pharyngeal swallowing reflex. The velopharyngeal sphincter rises and closes the path to the epipharynx, while the suprahyoid muscles push the larynx up and forward, and the epiglottis closes. Pushing the larynx forward and under the base of the tongue also causes the adduction of the vocal cords, which closes the glottis and thus prevents the penetration of food inside the larynx and further into the airways. These actions achieve separation of the digestive and respiratory pathways, pharyngeal filling, its passive emptying, and active pharyngeal muscle peristalsis $(1,11)$

\section{Esophageal phase}

The esophagus consists of striated and smooth muscles and its role is to transfer food to the stomach. With peristaltic movements, the food goes down. This is an involuntary phase of swallowing and is slower than the pharyngeal phase $(1,9,11)$.

\section{PATOPHYSIOLOGY}

Normal swallowing physiology is achieved by changes in pressure dynamics, tongue base and pharyngeal contraction exerts positive pressure on the bolus while simultaneously lifting the larynx anteriorly and superiorly opening the pharyngoesophageal segment allowing the bolus to pass into the esophagus. In patients with laryngotomy, the interaction of the base of the tongue and the contraction of the pharynx must compensate for the pressure of the closed pharyngoesophageal segment in order for the bolus to pass into the esophagus. This change in the physiology of swallowing leads to a slowing of bolus transit as well as to the accumulation of bolus remnants in the pharynx and is more common in patients who have also received chemotherapy (12).

Depending on the place of origin, we distinguish two basic forms of dysphagia: oropharyngeal and esophageal (13). Oropharyngeal dysphagia is an anatomically limited term and implies difficulties in the transit of food from the oral cavity to the pharynx and esophagus, where the 
spontaneous process of swallowing is initiated. As swallowing is one of the vital functions in which the larynx is involved, in order for the outcome of laryngeal cancer treatment to be considered positive, the patient needs to swallow efficiently and safely. Preservation of swallowing functionality is usually the most important goal of various surgical techniques (14).

Oropharyngeal dysphagia can be caused by damage to the oral cavity, pharynx and larynx, and the damage can be anatomical and functional. The location of the primary tumor will determine the changes in the different phases of swallowing. The larynx plays a central role in swallowing, but lesions in the oral cavity will interfere with the preparation of the bolus, its retention and transport to the pharynx. Lesions in the pharynx and larynx can lead to food aspiration (8).

\section{INFLUENCE OF RADIOTHERAPY AND CHEMOTHERAPY ON SWALLOWING FUNCTION}

Radiotherapy can cause mucositis and further ulcerative changes and pain. These symptoms are mostly temporary and will appear immediately in the first phase of radiotherapy treatment. Xerostomia is the most frequent and can last for years after radiotherapy, and fibrosis of the neck tissue can also develop (15). The study showed that radiotherapy (6500Gy) affects the following substructures of the larynx: thyroid cartilage, cricoid cartilage, epiglottis, suprahyoid epiglottis, infrahyoid epiglottis, supraglottic and subglottic part of the larynx, arytenoid cartilage, and arytenoid cartilage. Damage to these structures even 12 months after radiotherapy can lead to aspiration and swallowing disorders (16).

On the other hand, a study of the incidence of swallowing disorders in patients treated with radiotherapy alone showed that there were no significant changes in swallowing function compared to patients treated with both radiotherapy and chemotherapy (17). In patients treated with radiotherapy and chemotherapy, the incidence of swallowing disorders increased significantly over time through reduced mobility of the base of the tongue, limited movement of the tongue back and forth, reduced laryngeal closure, reduced laryngeal elevation, bilateral pharyngeal weakness, cricopharyngeal dysfunction (16). The study also indicated that 3 months after the end of chemotherapy, significant elements of swallowing disorders still remain, such as limited tongue movements back and forth and reduction of laryngeal elevation, and that they persist for up to 12 months after the end of chemotherapy. The amount of saliva dropped significantly as a result of chemotherapy, from $5.68 \mathrm{~g}$ at the beginning to $1.99 \mathrm{~g}$ after 3 months after the therapy and remained at the same amount for 12 months after the therapy $(1,18)$.
The latest study from 2020 included patients with laryngeal cancer who were treated only with radiotherapy and those treated with radiotherapy and chemotherapy. Swallowing function was examined at the beginning, followed by the examination after 6 weeks and three months after the end of therapy. The study showed that swallowing function decreased significantly both after 6 weeks and three months compared to the baseline status (19).

Studies on persistent symptoms of neck dysphagia, xerostomia, and fibrosis over a period of 8 years in patients after laryngeal cancer treatment with radiotherapy and chemotherapy indicate that $60 \%$ of patients had symptoms of dysphagia in the first year of therapy. That percentage was reduced to $36 \%$ after the fifth year and again increased to $48 \%$ after 8 years of follow-up. Xerostomia was recorded in $87 \%$ of patients during the first year, decreasing to $65 \%$ after 8 years of therapy, generally remaining stable after the second year. Neck fibrosis was recorded in $58 \%$ of patients one year after therapy. The percentage decreased slightly to 54 during the third year and increased again after 8 years. The results of this study indicated delayed effects of toxins after radiotherapy and chemotherapy (15).

\section{INFLUENCE OF SURGICAL TREATMENT OF LARYNGEAL CANCER ON SWALLOWING FUNCTION}

Surgical treatment of laryngeal cancer affects the physiology of swallowing, depending on the type of surgery that needs to be performed. Laryngectomies in the broadest sense are divided into total and partial $(19,20)$.

\section{PARTIAL LARYNGECTOMIES}

Partial laryngectomies consist of partial vertical laryngectomies, partial horizontal laryngectomies, and atypical laryngectomies. Partial vertical laryngectomies are used today in invasive glottic tumors. This group of laryngectomies includes: transcervical chordectomy, frontal partial laryngectomy, hemilaryngectomy, lateral partial laryngectomy, frontolateral partial laryngectomy and extended frontolateral partial laryngectomy (21).

Vertical partial laryngectomies are operations in which one side of the larynx remains spared from resection or is less resected, so it is possible that the laryngeal phase of swallowing is delayed. The epiglottis, although a supraglottic structure, is often used in the reconstruction of defects made by resection of tumor tissue. The relationship between the base and the tongue and the vestibule is not disturbed, and one intact side of the larynx retains its sphincter function. Patients with vertical partial laryngectomy do not have significant swallowing problems $(7,18)$. 
Swallowing problems in subtotal laryngectomies are pronounced. According to Jović (18), the basic principles of protection of the airway from bolus penetration, i.e. lowering of the epiglottis through the entrance to the larynx, sphincter closure and redirection of the bolus were violated. The pharyngeal phase of swallowing is disturbed and the patients aspirate their own saliva in the early postoperative period. Feeding in the first 8 days is done through a nasogastric tube and the rehabilitation begins after that period. The rehabilitation is significantly longer and amounts to 28.5 days.

Horizontal partial laryngectomy is applicable when the tumor is limited to the supraglottis. This type of surgery leads to laryngeal dysfunction. Supracricoid laryngectomy involves resection of both vocal cords, paraglottic space and thyroid cartilage. It is performed within the treatment of early-stage cancer or localized advanced glottic and transglottic cancer, while preserving the function of the larynx, more precisely swallowing, breathing and phonation (22)

There are two types of supracricoid partial laryngectomy (SKL). The first involves resection of the epiglottic and preepiglottic space and the second, which is based on sparing them. The main principle is resection of the vocal cords and ventricular folds as well as the entire thyroid cartilage while sparing at least one arytenoid cartilage. The first type of SKL refers to glottic tumors and the epiglottis and preepiglottic space are spared, and the space is reconstructed by suturing the cricoid cartilage to the epiglottis, hyoid bone and the base of the tongue. This procedure is called cricochiodoepiglotopexy. The second type of SCL is used in supraglottic and transglottic tumors where resection of the epiglottis and preepiglottic space is performed and is reconstructed by suturing the cricoid cartilage to the hyoid bone and the base of the tongue. This procedure is called cricochiodopexy $(7,22)$.

Extended supraglottic laryngectomies are interventions with the most intense swallowing disorder in the postoperative period. Resection of the arytenoid or resection of the base of the tongue are the most difficult operative supraglottic procedures from the aspect of postoperative functional problems with swallowing. The authors state that partial resection of the base of the tongue does not interfere with swallowing and that good reconstruction makes the movements of the base of the tongue and the rest of the larynx unrestricted. The average length of swallowing rehabilitation of operated patients with supraglottic laryngectomy is 5.6 days and the average time of achieving good swallowing is 18.6 days, although they state that recovery of swallowing function lasts up to 6 months after surgery (18).

\section{TOTAL LARYNGECTOMY}

Total laryngectomy involves the removal of all the structures that make up the anterior wall of the upper digestive tract, including all the cartilage of the larynx, epiglottis, hyodic bone, parts of the base of the tongue together with the neck muscles. The remaining tissue contains the pharyngeal mucosa and constrictor muscles. The most common types of laryngectomy closure are $\mathrm{T}$ closure and vertical closure. The direct relationship between the type of closure and swallowing disorders is not clearly defined, but the relationship between the type of closure and pressure in the middle part of the pharynx during swallowing is mentioned, as well as the presence of pseudoglottis $(14,23)$.

Removal of key anatomical structures and reorganization of remaining tissues has a significant impact on the physiology of swallowing. The absence of the larynx prevents the pharynx from shortening, the esophagus opening and the development of negative pressure, which helps the transit of the bolus. Bolus transit is hampered by pharyngeal reconstruction. Studies indicate increased intrabolic pressure in patients after total laryngectomy which reflects increased resistance to bolus transit through the newly reconstructed pharyngeal segment (23). Studies indicate the presence of obstructive structures such as a narrow lumen of the pharynx, the formation of pseudoglottis, cricopharyngeal dysfunction and strictures and stenosis, all of which interfere with the transit and flow of bolus. Changes in esophageal motility may be an additional factor in swallowing disorders in patients with total laryngectomy (24). During total laryngectomy, resection of the cricopharyngeal muscle is performed, which is the main muscular component of the upper esophageal sphincter, which after the procedure affects the reduction of maximum pressure and the duration of contractions during swallowing. By removing the larynx, the upper esophageal sphincter changes shape into a symmetrical ring, changing the ability to contract. Since cricopharyngeal contraction initiates esophageal peristalsis, changes in its function may explain the reduction and duration of esophageal contraction. Some authors believe that damage to the pharyngeal plexus, which is responsible for motor innervation of the esophagus, is also responsible for this (25).

Immediately after the intervention, additional conditions occur that complicate the physiology of swallowing. The study showed that $27 \%$ of total laryngectomized patients experience additional complications after surgical treatment, namely 1) edema of the pharyngeal mucosa, which usually resolves spontaneously within a few months of surgery; 2) fistulas whose incidence varies from 4 to $75 \%$ of laryngectomized patients; 3) functional barriers to bolus transit such as stenosis, strictures, obstruction, the presence of 
pseudoepiglottis or areas of excess tissue "pockets" where food and fluid accumulate, 4) return of nasal contents reported in $9 \%$ of patients after laryngectomy and explained is velopharyngeal incompetence; 5) poor motility of the esophagus; 6) reflux; 7) changes in language mobility in the region of the base $(26,27)$.

\section{CRANIAL NERVE DAMAGE AND SWALLOWING DISORDERS}

Five cranial nerves are involved in the swallowing process during the oral and pharyngeal phases: n.trigeminus (V), n. facialis (VII), n. glossopharingeus (IX), n.vagus (X) and n.hypoglossus (XII). If the listed nerves are affected by tumors or damaged due to the nature of the surgical intervention, they may be associated with swallowing disorders (9). Cranial nerves involved in swallowing send sensory information in nucleus Tractus Solitarius. Motor components are organized in the Nucleus Ambiguus, and together, Nucleus Tractus Solitarius and Nucleus Ambiguus comrise the swallowing center located in the medula in the brainstem, central pattern generator (28).

The N.trigeminus (V) has a motor and sensory branch. Motor innervation is directed to the masticatory musculature (m.temporalis, m.masseter, m. Medialis pterygoid, m.lateralis pterygoid), m. tensor tympani, $\mathrm{m}$.tensor veli palatini, m. digastricus (venter anterior), $\mathrm{m}$. mylohyoideus. The mandibular branch receives impulses from the lower lip, tongue, lower teeth and cheek mucosa. Damage to this nerve will significantly affect the function of chewing and opening the mouth $(11,29,30)$.

N.facialis (VII) innervates m.frontalis, m. orbicularis oculi, m.orbicularis oris, m.patysma, has a function in guttural innervation of the anterior two-thirds of the tongue and sensibility of the eardrum. In case of damage, it will give inadequate lip occlusion and salivation $(11,29)$.

N. glossopharingeus (IX) contains motor, sensitive and parasympathetic fibers. Motor fibres innervate the muscles of the soft palate and pharynx. They sensitively innervate the mucous membrane of the last third of the tongue, soft palate, pharynx, palatine tonsil and middle ear and transmit stimuli to the senses of taste. Parasympathetic fibers innervate the parotid salivary gland. The nerve belongs to the pharyngeal plexus, which controls the movement and constriction of muscles during bolus flow (29).

The N. vagus (X) contains motor, sensory, and parasympathetic fibers. It has a vegetative role and is characterized by a wide innervation field. Motor fibers innervate the transverse striated muscles of the soft palate, pharynx and larynx. Sensitive fibers innervate the skin of the external auditory canal, the mucous membrane of the pharynx, epiglottis, larynx, trachea and digestive organs this nerve courses through the pharygeal and laryngeal areas and can be injured during neck surgery. Recurrent laryngeal nerve innervates Upper Esophageal Sphincter and several portions of superior pharingeal constrictors $(29,30)$.

N. hypoglossus (XII) innervates the musculature of the tongue and m.geniohyoideus. With unilateral paralysis of the nerve, difficult tongue movements occur, while with bilateral paralysis, it is completely immobile and chewing is difficult $(11,29)$.

\section{SCREENING AND DIAGNOSIS OF SWALLOWING DISORDERS}

Screening for dysphagia includes early detection of signs and symptoms in patients who are at high risk of developing swallowing disorders. Screening procedures provide information on the presence of aspiration, inadequate swallowing, the presence of food debris in the mouth and pharynx, the presence of a hoarse voice, and coughing during or immediately after a meal. The purpose of screening is to determine the likelihood that swallowing disorder exists as well as the need for further assessment of swallowing $(14,31)$.

Examination methods can be instrumental or noninstrumental. For patients with signs and symptoms of pharyngeal dysphagia, instrumental examination methods provide more objective findings. Instrumental techniques are used to evaluate oral, pharyngeal, laryngeal, and esophageal functions as well as to determine the appropriateness and efficacy of treatment strategies (14). Videofluoroscopy or modified ingestion of barium is a radiological procedure that provides insight into oral, pharyngeal and esophageal function. The most comprehensive assessment of swallowing disorders and the recognized gold standard is modified barium ingestion. Fiberoptic endoscopic assessment of swallowing is a procedure that can be performed in the field but does not allow visualization of swallowing phases such as video fluoroscopy. A pressure gauge that monitors bolus pressure and creates pressure due to contractions at different points of swallowing is combined with video fluoroscopy for more accurate assessment and is the most important procedure that can identify the exact site of obstruction after laryngectomy (31-33).

\section{TREATMENT OF DYSPHAGIA AND QUALITY OF LIFE AFTER LARYNGEAL CANCER TREATMENT}

Swallowing disorders that affect $17-70 \%$ of patients treated for laryngeal cancer occur due to the presence of tumors and as a consequence of the treatment $(34,35)$. The swallowing disorder is the main concern of patients after 
laryngeal cancer treatment because it affects the quality of life. Improvement of swallowing function can be achieved by treatment and swallowing exercises. Studies indicate a correlation between the outcome of dysphagia treatment and smoking as well as a correlation with different types of surgery, after laser interventions dysphagia persisted for a short time (36). The speech pathologist is an important member of the multidisciplinary team in the treatment and rehabilitation of people with laryngeal cancer and the field of speech and swallowing therapy includes screening and initial assessment, diagnosis and pre-treatment planning, then treatment during the treatment and after the discharge and patient education. Compensatory and strategic techniques are used in the treatment of swallowing disorders, while surgical intervention is rarely an option (9).

In this chapter, we will try to connect physiological deficiencies, impaired swallowing function, compensatory techniques and strategies, therapeutic maneuvers and exercises after the laryngectomy $(9,32)$.

With total laryngectomy, we have no respiratory problems, the airway is redirected, but due to obstruction in case of stenosis, lack of pharyngoesophageal segment and altered peristalsis, we use compensatory strategies: changing posture, modifying the size and texture of the bolus, lying on its side, swallowing more. Therapeutic techniques and maneuvers used are opening the jaw while providing resistance, swallowing with effort $(9,14)$.

Supraglottic laryngectomies are characterized by incomplete movement of the base of the tongue, limited movement of the arytenoids, partial closure of the airways, impaired sensory function of the larynx. Swallowing is impaired in terms of delayed bolus transit, difficulty in lifting the structures involved in swallowing, reduced airway protection, reduced glottis closure, reduced pharyngeal clearance, weaker range of motion of the tongue base. Compensatory techniques are tilting the head, turning the head, lying sideways, modifying the texture and size of the bolus. Therapeutic maneuvers and exercises used are tongue retraction exercises, swallowing with effort, Masako maneuver, supraglottic swallowing, supersupraglottic swallowing $(1,32)$.

Supracricoid laryngectomies are characterized by a loss of piriform sinus volume, a vocal cord membrane that would close the anterior glottis, and a loss of ariepiglottic and ventricular folds. Swallowing is impaired at the level of bolus transit delay, dysfunction of lifting structures that participate in swallowing, reduction of airway protection, reduction of pharyngeal clearance. Compensatory strategies are tilting the head, turning the head, modifying the texture and size of the bolus, lying sideways. Therapeutic techniques and maneuvers used are supraglottic swallowing, supersupraglottic swallowing, effort swallowing, tongue base retraction exercises $(9,14)$.
In patients with hemilaryngectomy, there is unilateral resection of the larynx and partial closure of the respiratory organs. Impaired swallowing is at the level of unilateral weakness of the pharynx, reduced protection of the respiratory organs. Compensatory strategies are tilting the head, turning the head, modifying the texture and size of the bolus, lying sideways. Therapeutic techniques and maneuvers used are muscle strength training during expiration, vocal cord adduction exercises, thyropharyngeal strengthening through phonation, supraglottic swallowing, supersupraglottic swallowing, swallowing with effort $(14,18)$.

\section{CONCLUSION}

The human larynx achieves a complex function united through respiration, phonation and swallowing. Ingestion is complicated by loss or damage to the larynx or damage to motor and sensory function in addition to the side effects of radio and / or chemotherapy. Screening dysphagia after laryngectomy is often a missing link in the postoperative course of rehabilitation. Complications with partial laryngectomies can be silent aspiration and recurrent pneumonia, while in half of the patients with total laryngectomy, strictures, fistulas, and motility disorders significantly affect their quality of life. Swallowing treatment is important for patients undergoing laryngectomy, they should be advised before surgery and they should have a pretreatment of swallowing. Prophylactic exercises can enable a better recovery. The most important is the treatment after the surgery with periodic evaluation in order to achieve optimal outcomes, with possible education in the field of dietary modification.

\section{REFERENCES}

1. Logemann J. Evaluation and treatment of swallowing disorders. Austin: Pro-ed, 1998.

2. Groher M, Crary, M. Dysphagia: clinical managment in adults and children. 2nd ed. St. Louis: Elsevier, 2016.

3. Larynx. Source: Globocan 2020. The Global cancer observatory. Lyon: International Agency for Reaserch on Cancer; Geneve: World Health Organization, 2020. (https:/gco.iarc.fr/today/data/factsheets/cancers/14Larynx-fact-sheet.pdf).

4. Ferrand, T. Voice disorders: scope of theory and practice. New York: Pearson, 2019.

5. Bumber Ž, Katić V, Nikšić Ivančić M, Pegan B, Petric V, Šprem N. Otorhinolaryngology. Zagreb: Naklada Ljevak, 2009. (in Croatian).

6. Myers J, Hanna Y, Myers N. Cancer of head and neck. Philadelphia: Wolters Kluwer Health, 2017. 
7. Graciano J, Sonagli M, Clemente da Silva G, Fischer A, Chone T. Partial laryngectomy in glottic cancer: complications and oncological results. Braz J Otorhinolaryngol 2016; 82: 275-80.

8. Zenga J, Goldsmith T, Bunting G, Deschler G. State of the art: rehabilitation of speech and swallowing after total laryngectomy. Oral Oncol 2018; 86: 38-47.

9. Krishnakumar T, Iyer S, Menon R. Dysphagia managment in head and neck cancers. Kochi: Kerala Institute of Medical Sciences, 2018.

10. Matsuo K, Palmer J. Anatomy and physiology of feeding and swallowing - normal and abnormal. Phys Med Rehabil Clin N Am 2008; 19: 691-707.

11. Sasegbon A, Hamdy S. The anatomy and physiology of normal and abnormal swallowing in oropharyngeal dysphagia. Neurogastroenterol Motil 2017; Neurogastroenterol Motil 2017; 29: e13100.

12. Lorenz KJ Rehabilitation after total laryngectomy-a tribute to the pioneers of voice restoration in the last two centuries. Front Med (Lausanne) 2017; 4: 81.

13. Vuković M. Communication disorders in traumatic brain injury. Belgrade: Planeta print, 2012. (in Serbian).

14. Desuter G. Oropharingeal dysphagia. Brussels: Springer, 2019.

15. Baudelet M, Van den Stehen L, Tomassen P. Very late xerostomia, dysphagia, and neck fibrosis afrer head and neck radiotherapy. Head Neck 2019; 41: 3594 603.

16. Petras G, Rademaker W, Refaat T, et al. Dose-volume relationship for laryngeal substructures and aspiration in patients with locally advanced head-and-neck cancer. Radiat Oncol 2019; 14: 49.

17. Gioacchini FM, Tulli M, Kaleci S, Bondi S, Bussi M, Re M. Therapeutic modalities and oncologic outcomes in the treatment of T1b glottic squamous cell carcinoma: a systematic review. Eur Arch Otorhinolaryngol 2017; 274: 4091-102.

18. Jović R. Influence of resection of laryngopharyngeal structures in malignant laryngeal tumors on swallowing function. Doctoral dissertation. Novi Sad: Faculty of Medicine, 1988.

19. Im I, Carnaby GD, Takahashi N, Dungan S, Crary MA. Clinical Swallowing Profile Change in HNC Patients Treated with C/RT. Laryngoscope 2021; 131: E1873E1880.

20. Petrovic Lazic M. Phonopedia. Belgrade: Naučna knjiga, 2001. (in Serbian).

21. Prgomet D, Katić V. Malignant tumors of the larynx. Zagreb: Naklada Ljevak, 2009. (in Croatian).
22. Castro A, Gavilan J. Supracricoid laryngectomy. In: Fagan J, ed. Open Access Atlas of Otolaryngology, Head \& Neck Operative Surgery. Cape Town: Division of Otolaryngology, Groote Schuur Hospital, 2017. (https:/vula.uct.ac.za/access/content/group/ba5fb1bdbe $95-48$ e 5-81 be-586fbaeba $29 \mathrm{~d} /$ Supracricoid $\%$ 20laryngectomy.pdf).

23. Maclean J, Szczesniak M, Cotton S, Cook I, Perry A. Impact of a laryngectomy and surgical closure technique on swallow biomechanics and dysphagia severity. Otolaryngol Head Neck Surg 2011; 144: 21-8.

24. Ward EC, van As-Brooks CJ. Head and neck cancer : treatment, rehabilitation, and outcomes. San Diego: Plural Publishing, 2015.

25. Choi C, Hong P, Kim B, Yoon C, Nam I. Changes of oesofageal motility after total laryngectomy. Otolaryngol Head Neck Surg 2003; 128: 691-9.

26. Singh R, Karantanis W, Fadhil M, Dow C, Robinson $\mathrm{R}$, Jacobson I. Meta-analysis on the rate of pharyngocutaneous fistula in early oral feedeng in laryngectomy patients. Am J Otolaryngol 2021; 42: 102748 .

27. Ahn D, Lee J, Sohn H. Ultrasonographic swallowing examination for early detection of neopharyngeal fistula after salvage total laryngectomy: a preliminary study. Head Neck 2019; 41: 1804-8.

28. Steuer I, Guertin PA. Central pattern generators in the brainstem and spinal cord: an overview of basic principles, similarities and differences. Rev Neurosci 2019; 30: 107-64.

29. Jovanović V, Jeličić A. Human anatomy-head and neck. Belgrade: Savremena administracija, 2000.

30. Standring S. Gray's Anatomy e-book The anatomical basis of clinical practice. Amsterdam: Elsevier, 2020.

31. The Practice Portal. Rockville: The American SpeechLanguage-Hearing Association, 2020. (https://www.asha.org/practice-portal).

32. McCoy Y, Wallace T. The adult dysphagia. San Diego, Plural Publishing, 2019.

33. Groher E, Crary A. Dysphagia: clinical menagment in adults and children. 2nd ed. St. Louis: Elsevier, 2016.

34. Maclean J, Cotton S, Perry A. Post-laryngectomy: an australian study of prevalence and self reports of swallowing function after total laryngectomy. Dysphagia 2009: 24. 172-9.

35. Galli J, Marchese R, Cesare D, et al. Impact of tracheal tube on swallowing in post-operative head and neck cancer patients: scintigraphic analysis. Dysphagia 2020. (Online ahead of print). (doi: 10.1007/s00455020-10222-y).

36. Meyer A, Dietz A, Wollbruck D, Oeken J, Danker H, Meister E, Singer S. Swallowing disorders after partial laryngectomy. HNO 2012; 60: 892-900. 